\title{
Strategies for Transforming Rural Areas and Ensuring Effective Governance in Local Governments in Nigeria
}

\author{
S.O. Uhunmwuangho, Ph.D \\ L E C T UR E R \\ INSTITUTE OF PUBLIC ADMINISTRATION AND EXTENSION SERVICES \\ UNIVERSITY OF BENIN \\ BENIN CITY, NIGERIA Uhunmwuangho4you@yahoo.com \\ Stanley Aibieyi, Ph. D \\ SENIOR LECTURER \\ INSTITUTE OF PUBLIC ADMINISTRATION AND EXTENSION SERVICES \\ UNIVERSITY OF BENIN \\ BENIN CITY, NIGERIA \\ saibieyi@yahoo.com
}

\author{
Accepted: June 19, 2013 Published: July 19, 2013 \\ Doi:10.5296/ijld.v3i3.4030 URL: http://dx.doi.org/10.5296/ijld.v3i3.4030
}

\section{A b stract}

It is believed that the only reasonable form of development is the development that comes from within, sustainable development that comes through the will and desires of the people. The ideas behind the creation of Local Government in Nigeria is that the people at the local level are assumed to have the fullest awareness of their needs. Every local jurisdiction has its unique economic, social and physical characteristics and its historical tradition which are better understood by its people. Thus, the Local Government Areas are created to provide the services which the Federal and State Governments cannot easily undertake due to their remoteness from the local communities. Therefore, the concept of local government is to bring governance closer to the people at the grassroots, with the aim of caring for the socio-economic and development needs of local populace. Over the years, it has been observed that massive rural-urban migration and over congestion are heating up lives in the cities. Others have contented that Local Governments are docile in terms of aggressive revenue collection to augment allocations from the federation account which they get on monthly basis. Yet, others hinged Local Governments' abysmal revenue generation on dishonesty on the part of council revenue collectors, who, in most cases, misappropriate collections made on behalf of the council. In the face of these charges or allegations, it has become pertinent to investigate why Local Governments in the country have poor revenue generation efforts. The thrust of this paper therefore is to find a lasting solutions to the financial problems hindering local governments in Nigeria, most especially strategies to ameliorate the over-dependence on allocation for the up-keep of the Local Government. The paper also recommends amongst others, that any official who divert local government funds to their personal purse should be punished in accordance with the law of the land, use of council staff for revenue collections should be encouraged and stop using agents who are not council staff. The paper concludes that 
undoubtedly, for Local Governments to be able to perform these functions creditably, they need sufficient funds.

Keywords: Local, Relevant, Mobilize, Revenue, Autonomy, Allocation.

\section{Introduction}

It is believed that the only reasonable form of development is the development that comes from within, development that comes through the will and desires of the people. The ideas behind the creation of Local Government in Nigeria is that the people at the local level are assumed to have the fullest awareness of their needs. Every local jurisdiction has its unique economic, social and physical characteristics and its historical tradition which are better understood by its people. Thus, the Local Government Areas are created to provide the services which the Federal and State Governments cannot easily undertake due to their remoteness from the local communities (Uhunmwuangho and Epelle, 2008)

The concept of local government in Nigeria has had a very long history. Though the 1976 revolutionary legislation introduced by the then military administration of General Olusegun Obasanjo standardized and transformed the cacophony of local administrations existing around the country consequently catapulting it to the centre of national attention and discourse, yet it is on record that some form of "local government" had existed right from 1914 (1912 in the Northern Protectorate) when Sir Fredrick (later Lord) Lugard introduced the indirect rule system in the newly amalgamated Nigeria (Sani, 1992:15-7).

It is interesting to note however that despite the change in nomenclature and modus operandi from Indirect Rule system through post-independence Native Authorities to the 1976 magna carta local government system, very little achievements have been the products of these governmental apparati thereby raising calls in some quarters for the scrapping of this (third) tier of go vernment). This embarrassing gap between citizens' aspiration and available results from local administrators needs to be attacked and corrected in order to ensure that local governments assume the intended role of drivers of change in the rural communities where they are located. Indeed, there is no gainsaying the fact that all the reform instruments following the 1976 ground-breaking legislation has been primarily inspired by the national desire to make the local governments not only economically viable but politically efficient and socially positioned to deliver quality and efficient services to the people at the grassroot. Anything short of this amounts to short-changing the people and traumatizing their ego.

As has been mutted above, the failure of the local government system in the country is not a function of paucity of the enabling laws as there is a plethora of this in our statute books. However, the problem seems to lie in the hazy and inarticulate identification of the strategies and mechanisms which our local "managers" are to apply in their attempt to bring about goal-driven and people-oriented changes at the local level,

In this era of e-government and globalization with countries in a rat-race competition to develop all sectors of their economy so that one will serve as a market for the other our rural sector must not be left to totter in the hands of ill-equipped and hence inefficient administrators easily satisfied with modest achievements and driven by goals which seemingly universal are however short (or at least, medium) term in scope. The point of departure of this work is on how to isolate and amplify those pulsating skills, attitude and strands of thought that will galvanize our local administrators into effective managers of change at the local government levels (Uhunmwuangho and Epelle, 2008). The development ratio between the urban cities and the rural dwellings in this country is abnormally lopsided and highly unacceptable for even development of this nation.

In view of the leading role local governments can play in national and sustainable development there is need for local administrators to sit up and live up to 
the expectations of the people in contrast to the current scenario where local government functionaries breach public trust, divert public resources entrusted to their care and leave the people more impoverished.

\section{The Problem}

The development ratio between the urban cities and the rural dwellings in this country is abnormally lopsided and highly unacceptable for even and sustainable development of this nation in particular and Africa in general. This lopsided development policy has created many avoidable problems some of which are massive rural- urban migration thereby over congestion and heating up the lives in the cities, infrastructural decay at the rural areas due to total neglect and abandonment, mass poverty in the country due to lack of proper harmonization of the nation's resources (Ibhawaeghele, 2012)

The important question at this juncture thus relates to how much impact local governments have made on the lives of the people in their areas vis-à-vis the high expectations from the latter. No doubt, with the substantial increase in revenue accruing to local governments for quite sometime now, some of them have been able to embark on significant projects in various spheres with positive impact on social infrastructure, agriculture, health, industries, and water supply. However, available facts still show that our local governments in Nigeria cannot be counted among the high-performing ones in the world, indeed, not even among the average performing local governments in the third world. Rather, our local governments have been sharply criticized for poor performance in terms of scope, depthand quality of services, particularly in such areas as provision of infrastructure, medical and health services, water supply, waste disposal and many other services listed in the 1999 Nigerian Constitution. In fact, some of the Constitutional functions are not performed at all. And as a former Edo State top government official (Egonmwan, 1984) observed:

With the massive increase in the revenue from the

Federation Account following the 1976 reform, many

Local governments engaged in wreckless spending on

grandiose projects which have little relevance to

the needs of the local communities. With the

oscilliation and dwindling of revenue from oil,

many of the se projects became abandoned

leading to colossal waste of resources. There can be

hardly any local government area in Nigeria today

where corpses of abandoned projects are not found.

The spend ing of most local governments is not only characterized by waste but also by very pervasive corruption. Although corruption is described as a cankerkworm found in every facet of the Nigerian society, it is particularly worrisome at the local government level. Most Nigerians believe that public funds are just shared among government officials, cronies and their political associates. This may appear exaggerated. But what is clear though is that corruption is so entrenched at the third tier of government that it is obvious to everybody that there is not much development to show for the huge financial resources that have accrued to the councils. Thus, the views of Nigerians collated in the Political Bureau Report in 1987 still remain valid up till today: that despite the strategic importance of local government to the national development process, its contribution has been minimal. And only recently, in "The Guardian" newspaper, former Governor Ikedi Ohakim of Imo State gave a damning verdict on the performance of local governments: 
It is obvious that the council administration is not working.

The council system has failed woefully in Nigeria. And if nothing is done to salvage the situation, the country will continue to have problems at the grassroots. We have wasted money to the extent that the council system has become an enterprise of a different dimension where some 'big men' try to install their housemaids and houseboys so that they can be making returns ... The council system has enriched only few individuals who are now being chased by the masses on the streets (Guardian, $27^{\text {th }}$ December, 2007).

This negative perception of local governments constitutes a monumental challenge not only to the elected local government functionaries in the current democratic dispensation but to every Nigerian concerned with the slow pace of development in the country in spite of our abundant resources (Uhunmwuangho and Epelle, 2008).

Consequently, this study is focused on the need to bring to the front burner critical issues that have served as the missing link in previous attempts to re-engineer local governments in the country to spearhead sustainable development at the rural level.

\section{Local Government and Socio-Economic Development}

In many countries, Nigeria included, the local government is widely acknowledged as a viable instrument for rural transformation and for the effective delivery of social economic services to the people. According to Obadan (2008):
the local government in Nigeria is
a well-recognized third-tier of government.
It is administration or government at the grass roots
or local level. At this level, government is expected
to be very close to the people, both in the
villages, settlements and towns, and to impinge on
the day-to-day life of the common-man. Furthermore,
local government is expected to be actively involved
in the overall national development objective of
achieving a broad-based social and economic
development and securing an optimum utilization
of manpower.

Local governments are strategically located to deliver on the functions spelt out for it for three main reasons:

- $\quad$ proximity to the people;

- $\quad$ greater responsiveness to the needs of the local populace; and

- $\quad$ simplicity of operation in that local government organizations are usually not complex.

Although local government has existed in one form or the other in Nigeria for quite sometime, it was after a number of reforms, particularly the 1976 reforms and the subsequent ones, that it acquired the respectable status it now enjoys today. One compelling reason for the reforms was the need to make local governments perform their economic development functions better. Some major developments in the local government system since the 1976 reforms are as follows: 
(i) Unlike previously, local governments have now been assigned and guaranteed certain specific developmental roles in the 1979, 1989 and 1999 Constitutions of the Federal Republic of Nigeria.

(ii) In order to enable local governments perform their functions, a constitutional backing has been provided for them to receive a statutory proportion of funds in the Federation Account as well as the states who are to contribute a proportion of their internally generated revenue to local governments in their domain. Accordingly, the revenue share of local governments in the Federation Account has progressively increased from 10 percent in the early 1980s to 15 percent in 1990. As at 2012, this proportion stood at 20 percent. Currently, the revenue sharing formula from the Federation Account is as follows:
(a) Federal Government $=50 \%$
(b) State Government $=24 \%$
(c) Local Government $\quad=20 \%$
(d) SpecialFunds $=6 \underline{.5 \%}$

Total $=\underline{100 \%}$

The Valued Added Tax (VAT) is also currently distributed as follows:

(1) Federal Government $=15 \%$

(2) State Government $=50 \%$

(3i) Local Government $\quad=35 \%$

Source: Federal Office of Statistics, Benin City

(iii) In accordance with constitutional provisions, local governments have become involved in development planning.

(iv) In order to carry the presidential system of government to its logical conclusion, the system has been extended to administration at the grass-root level. This has ensured a large measure of autonomy to local governments as a veritable third-tier of government.

The various constitutions of the Federal Republic of Nigeria right from 1979 have spelt out the functions of local government councils. A close look at the list of functions shows that they are in two groups: those which are to be performed exclusively by local governments; and functions which can be performed concurrently by both the state and local governments. These functions of local governments may be grouped into four categories, for them to be properly appreciated:

(a) Regulatory and licensing functions - these include regis tration of birth, death and marriages, control and regulation of shops, kiosks, and restaurants.

(b) Social service functions which include the provision of health facilities, primary, vocational and adult education, refuse disposal, and road construction

(c) Protective functions include maintenance of parks and gardens, cemetaries, et-cetera.

(d) Economic functions which include provision of market stalls, investing in business ventures, involvement in agriculture and above all formulation of economic planning and development schemes for the local government area.

Within this framework, it is not surprising that local government in the country has been seen as a veritable third tier of government, hence prompting attempts to convert them into 'development-oriented' local governments. A sustainable and development-oriented local 
government is expected to be a vehicle for the provision of goods and services which are the necessary pre-requisites for sustainable development. In this context, a local government should be able to render services to and provide facilities for the people in a manner that every individual will have uninhibited access to the services so rendered and the facilities provided.

However, there have been lopsided development policy which has created many avoidable problems some of which are enumerated below:

(a) Infrastructural decay at the rural areas due to total neglect and abandonment. All the natural resources are rural based.

(b) Massive poverty in the country due to lack of proper harmonization of the nation's resources

The table below also buttressed this point that about 70 million Nigerians are poor:

\section{Table Two}

\begin{tabular}{|c|c|c|}
\hline S/No & Year & Figure (million) \\
\hline 1. & 1980 & 28.1 \\
\hline 2. & 1985 & 46.3 \\
\hline 3. & 1992 & 24.7 \\
\hline 4. & 1996 & 65.6 \\
\hline 5. & 1999 & 70 \\
\hline 6. & 2004 & 54.4 \\
\hline
\end{tabular}

Source: National Bureau of Statistics (2008)

However, the Regional or Geo-political breakdown of the poverty rate ind icate thus:

Table Three

\begin{tabular}{|c|c|c|}
\hline S/No & Geo-political Zone & Percentage \\
\hline 1. & North East & 72.2 \\
\hline 2. & North West & 71.2 \\
\hline 3. & North Central & 67.0 \\
\hline 4. & South West & 43.7 \\
\hline 5. & South-South & 31.5 \\
\hline 6. & South-East & 26.7 \\
\hline
\end{tabular}

Source: National Bureau of Statistics (2008)

From the above tables, one would easily deduce that over concentration of all developmental efforts at the centre to the neglect of the rural areas is largely responsible for the mass poverty in the country. In the Northern part of the country, much emphasis is placed on extensive urban development to the detriment of the rural dwellers. It clearly shows the poverty rate as highest in that geo-political zone. One of the things that impresses the author in this analysis is the dynamism of the people of the South-East geo-political zone who, inspite of the circumstance of that region's traumatic experience in the history of this country, still managed to attain the least percentage in the poverty rating.

In order to succeed in the efforts to develop their areas, local government functionaries must identify, harness and exploit crucial ingredients of social-economic development in these areas, namely, natural resources, capital, enterprise, technology, markets, and infrastructure.

\section{Strategies For Ensuring Effective Governance At The Local Government Level}

In general, if local governments are to be tools for effective and sustainable governance and development agents, they must adopt the following strategies and 
exhibit adequate cope mechanisms for the enormous challenges that confront them at that level. Some of these strategies and challenges include:

(i) Efficient mobilization of resources - human, material and financial resources must be effectively and efficiently harnessed if sustainable development must occur at that level.

(ii) Collection of vital data on population, demographic structures, housing, birth and death rates, must be adopted as a basis for effective planning and systematic development.

(iii) Provision and maintenance of physical infrastructure such as roads, bridges, culverts, water supply, storage units; and institutional infrastructure like human capacity building, seminars and workshops. Infrastructure plays a very significant role not only in stimulating rural production with uncountable multiplier effects, it also provides the environment for increased employment and the diversification of economic activities in these areas (Uhunmwuangho and Epelle, 2008).

(iv) Playing a complementary role with other levels of government and non-governmental agencies in the area of provision of rural roads, water supply and sanitation, housing and rural electrification, as well as providing employment opportunities.

(v) Creation of supportive institutions which stimulate agricultural and ind ustrial development: for example, local governments can provide ind ustrial estates within their areas of operation; they can sponsor small and medium-scale pioneer industries which utilize raw materials in their locality; they can establish employment registration centres and enter into joint-venture businesses with private investors or collaborate with other local governments to undertake major economic and commercial projects.

(vi) Economic planning: This is a strategy by which local governments can work towards accomplishing total social and economic development of their areas. Through effective planning local governments should be able to identify the needs of the people using a bottom-up approach strategy and then formulate and implement policies which satisfy those needs. To do this, local governments will have to evolve ways of combating the problems which militate against effective planning at that level, namely, poor orientation and attitude to planning, lack of specialized planning units, paucity of professional planners, economists and statisticians; structure of local government responsibility and expenditures which reflect a preponderance of service delivery and recurrent expenditures such that not much resources are available for meaningful development projects- not least is the cankerworm of corruption (Idode, 1989:22).

Sequel to the fact that a good analysis of the problem leads to an objective and result-oriented enunciation of solutions, we believe that sustainable and rural development is possible in Nigeria only if the present government transcends the payment of lip-service to the phenomenon and commits itself wholeheartedly to it just as it committed itself recently to the implementation of the neo-liberal reforms of the last five years. Consequently, the following for accelerated rural development in Nigeria:

1. Robust Central Co-0rdination: Since rural development is of national benefit, the political leadership in the centre has a salient role to play in bringing it about. In China, this was achieved with the help of a strong political ideology that mobilized the vast majority of the people for a socialist transformation of the society. In Nigeria, the 
central government can kick-start rural development by ensuring that its energy programme and rural telephony project are implemented faithfully. With this done, it can then go ahead to set a national minimum standard and checklist for states and local government councils to follow.

2. Effective Local Council Organisation: Rural development should be left in the hands of the local government councils. As already noted, local government councils being the closest to the people understand their needs better than the far located central and state governments, and hence can easily modify their policies to meet these needs. They can also easily mobilize the people to participate in co-operatives and self-help projects. In the light of these facts, it is therefore necessary that they be given the free hand not only to mobilize the rural people as noted, but to also articulate and implement programmes that meets the people's need sui generis. Such free hand must necessarily involve extricating the local councils from operating a Joint Account with the state governments because through such accounts, the former had been fleeced of valuable funds that could have been used to develop the rural areas of the country.

3. Involvement of The Local People: According to Idode (1989:102), since development cannot be imposed in the form of a government fiat from above, it must necessarily have to carry the people along with it if it is not to be sabotaged by them. Earlier rural development programmes as we have seen ignored the people treating them as if they were themselves obstacles to development. This should not be so. Local community participation is essential for any sustained effort at rural development in Nigeria. This is because experience has shown that people tend to be more committed to goals in which their inputs were initially sought. More importantly, group arrangements like co-operative and thrift societies while allowing for active community participation in rural development efforts also serve as veritable channels for credit and input supplies from governmental and non-governmental sources (World Bank Report, 1975:6-7).

4. Diversification Of The Rural Economy: As earlier noted, one of the problems besetting earlier rural development efforts in the country is the misguided emphasis on parochial agricultural programmes as if though food can be produced in a vacuum. If we are to achieve success in our rural development plans, then we need to establish cottage industries for consumer goods and textile manufacture. All these will provide more income for the local people, improve their standard of living, attract other ancillary services like banks and insurance companies and more importantly mitigate the fleeing of rural areas by youths with all its attendant consequences on the already congested urban centres (Ola, 1995).

5. Provision of Social Services: According to the World Bank (1975:6), public sector spending in most developing countries tends to be urban-biased as it favours urban dwellers more than the rural areas in the provision of social infrastructure. It is believed that with a reversal in emphasis government will not only make the rural areas more habitable hence helping to stem rural-urban drift, but will also make it (the rural areas) investor-friendly as already noted.

6. Land Reforms: Land policy, as noted by the World Bank (1975:6), has serious implications for the rural people as their level of income is dependent on the extent to which they control the land and its products. Consequently, such land reforms, like the Land Use Act of 1976, that seeks to expropriate local people of their lands is bound to have adverse effects on peasants. It is our belief in this paper that any attempt to effectively plan for rural development in Nigeria must address the problems engendered by the alienation of the peasantry from their lands by the forces of bourgeois exploitation.

The quality of life of the people depends on how efficiently the various local government functions and roles, especially the social services functions and economic functions are 
performed. Most of these functions have serious implications for the health, safety and socio-economic well-being of the local populace (Adefolalu, 2001:67). Therefore, if local administrators are efficient in their social service delivery functions, if they demonstrate a high degree of commitment in providing and/or protecting public utilities in their care and if they are judicious in utilizing resources to ensure increase in the income of the rural people, an acceptable distribution of income, an increase in the availability of and range of life-saving goods, as well as create job opportunities at the local level, then there will be little tendency, other things being equal, for people to complain and/or lose hope about local governments.

\section{Conclusion}

It is believed that the only reasonable form of development is the development that comes from within, sustainable development that comes through the will and desires of the people. The ideas behind the creation of Local Government in Nigeria is that the people at the local level are assumed to have the fullest awareness of their needs. Every local jurisdiction has its unique economic, social and physical characteristics and its historical tradition which are better understood by its people. Thus, the Local Government Areas are created to provide the services which the Federal and State Governments cannot easily undertake due to their remoteness from the local communities. Therefore, the concept of local government is to bring governance closer to the people at the grassroots, with the aim of caring for the socio-economic and development needs of local populace.

As the level of government closest to the grass-roots, our local government has a gigantic role to play in mobilizing resources to ensure the transformation of the local government area and an environment that enables the people to meet their basic needs. Good infrastructure will enhance agricultural productivity and stimulate agro-industrial activities. The need to ensure efficient utilization of resources through the avoidance of corruption should be uppermost in the minds of our local government functionaries. Corruption retards societal growth and development and increases poverty (Iyoha, 2008).

\section{Recommendations}

Specifically, the following recommendations may be considered:

(i) Institutionalize planning at the local government level. Have a three-year development plan (fashioned in the form of a rolling plan) with significant inputs from the populace. To this end, there is need for effective institutions and structures for community participation in the planning, execution and financing of social and economic projects. The local government may also consider establishing a planning board/committee, consisting of different stakeholders, under the leadership of the local government chairman. Such a committee can help to identify and evaluate sound development projects and programmes for incorporation in the local government's development plan, co-ordinate the local government's draft programmes, and monitor the progress and problems of the local government's projects and programmes.

(ii) Set up due- process committee in the local government. The due process compliance principle is one of the few commendable reforms of the last Obasanjo administration. The features of due process are such that can minimize corruption in public procurement and contract award, and yield substantial value for money.

(iii) Promote small and medium enterprises (SMEs). Within the framework of proper development planning there is need to promote SMEs as a major instrument of economic empowerment of the people. The local government 
may need to set up a Small and Medium Industries Development Agency to promote and address the problems of SMEs in the spheres of sourcing for cheap finance, skills acquisition and training, research, market sourcing and access, as well as linkages with suppliers. Once the enabling and investment-friendly environment and support are provided, SMEs can be a veritable instrument for wealth creation, poverty reduction and employment generation in the local government.

Generally, it can be argued that there is no shortage of ideas on how to achieve and/or overcome the above challenges and bring about sustainable development, socio-economic and transformation of local governments in Nigeria. Only the will and commitment to development of those in political authority appear to be the elixir. In the past, various stakeholder groups have proferred ideas on desirable strategies to develop the local government area. These ideas should be dusted and tried-out.

Finally, the local government leadership should not succumb to various political and social pressures that are anti-people and anti-sustainable development.

\section{R e fere nce $s$}

Adefolalu, A. A. (2001) "Integrated Rural Development, Meaning, Scope and Components", Conference Paper on Integrated Rural

Development and Women in Development, held on $21^{\text {st }}$ June 2003 in Benin City.

Constitution of the Federal Republic of Nigeria (1999)

Egonmwan, P. (1984), Principles and Practice of Local Government in Nigeria, Benin City, S.M.O. Aka \& Brothers Press.

Ibhawaegbele, F.O. (2012) Rural Transformation: A Matter of Lip Service "In The Catholic Evangelist 's (ed) Vol. 18 No. 140 p.6 Benin City, Floreat System Pres s

Idode, J.B. (1989) Rural Development and Bureaucracy in Nigeria, Nigeria, Longman.

Ola, R.F. (1995) Nigerian Political System (Inputs, Outputs and Environment) Ambik Press, Benin City.

Iyoha, F.E. (2008) Local Government and Rural Development, Sylva Publications Limited, Lagos

Obadan, M.I. (2008), Inauguration of Chairman of Esan South Local Government Area, Benin Paper presented at the Inauguration of Newly Elected Local Government Chairmen in Edo State, Benin City

Sani, H.A. (1992) Local and Urban Administration in Nigeria, Okene-Kogi State, Habibu Angulu Sani and Sons Enterprises

The Guardian Newspaper, (2007) How To Make Local Council Work, 27 $7^{\text {th }}$

December, p10 
Uhunmwuangho, S.O and Epelle, A. (2007) "Problems and Prospects of Rural

Development Planning in Nigeria 1966-2006" in International Journal of Communication, Vol. 7 No. 3

Uhunmwuangho, S.O. and Epelle A. (2008) Strategies for Managing Challenges and Ensuring Effective Governance in Local Governments in Nigeria, Nigerian Benin, Journal of Citizenship Education Vol.7 No.2.

World Bank (1975) Rural Development, Sector Policy Paper, February. 